\title{
Kromit ve Manyetit Cevherlerinin Sanatsal Camlarda Kullanımı
}

\section{Using of Chromite and Magnetite Ores in Artistic Glasses}

\author{
Emir Özkaya, ${ }^{\text {a }}$ Selvin Yeşilay ${ }^{\text {b,* }}$ \\ a Anadolu Üniversitesi, Güzel Sanatlar Fakültesi, Cam Bölümü, 26470, Eskişehir/Türkiye. \\ ORCID: 0000-0003-3522-5851 \\ b Dr. Öğr. Üyesi, Anadolu Üniversitesi, Güzel Sanatlar Fakültesi, Cam Bölümü, 26470, Eskișehir/Türkiye. \\ ORCID: 0000-0002-8217-3874
}

\section{MAKALE BİLGİSI}

\section{Makale Geçmişi:}

Başvuru tarihi: 20 Aralık 2017

Düzeltme tarihi: 04 Şubat 2018

Kabul tarihi: 12 Şubat 2018

\section{Anahtar Kelimeler:}

Cam Sanatı

Plastik Sanatlar

Dekorasyon

Manyetit

Kromit

\section{A R T I CLE I N F O}

\section{Article history:}

Received 20 December 2017

Received in revised form 04 February 2018

Accepted 12 February 2018

\section{Keywords:}

Glass Art

Plastic Arts

Decoration

Magnetite

Chromite

\section{ÖZ}

Hem estetik hem dekoratif bir malzeme olan cam özellikle sanatsal ifade için eşsiz bir seçenektir. Cam sanatçıları eserlerinin estetik değerini geliştirmek için üretim aşamasında veya nihai ürün üzerinde çeşitli dekorlama teknikleri kullanmaktadırlar. Camların renklendirme ve dekorasyonunda kullanılan ticari pigmentler yüksek sıcaklıklara dayanıklı olmak zorundadırlar, bu nedenle üretim maliyetleri yüksektir. Bu çalıșmada, renklendirici saf oksit ve bileşiklere kıyasla maliyeti daha düşük olan seramik hammaddeler kullanılmış, sanatsal camlardaki renk ve doku etkileri araştırılmıştır. Bu tür farklı dekoratif çalışmalar özgün bireysel tasarımların yolunu açmaktadır. $\mathrm{Bu}$ doğrultuda manyetit ve kromit cevherleri belli bir tane boyutuna getirilmiş ve daha sonra sanatsal camlardaki etkileri incelenmiştir. Manyetit ve kromit kullanımı sıcak cam yüzeylerine dereceli renk tonları ve homojen dağılım etkisi kazandırmıştır.

\section{A B S T R AC T}

Glass, both aesthetic and decorative, is a unique choice for artistic expression. Glass artists use various decorating techniques on the production stage or the final product to improve the aesthetic value of their works. The production cost of commercial pigments for coloring and decoration purposes in glass is an important part of glass production. These pigments must be able to withstand high temperatures, which leads to high production costs. In this study, ceramic raw materials with lower cost compared to colorant pure oxide and compounds in hot glass blowing technique were used and color and texture effects on art glass were investigated. Such different decorative works open the way to individual designs. In this direction, the magnetite and chromite ores were milled to a certain grain size and then their effects in different artistic glass designs were examined. The results show that magnetite and chromite can be used in the production of individual artistic glass due to their ability to provide graded color shades on the hot glass surfaces and to provide a homogeneous distribution effect.

\section{Giriş}

Malzeme ile keşfetme yaklaşımı, genellikle, sanatçının doğru diye bildiklerimize meydan okuyan sanat eserlerinin bünyesine veya yüzeyine yaklaşabilmek için malzemenin nüansını ve mizacını araştırdığı deneysel ve uygulamaya yönelik tasarım yaklaşımını içerebilir. Bir sanat eseri malzemelerin doğasını ve özelliklerini anlamamıza yardım eder (Abidin, 2015: 174).
Günlük yaşantımızda camdan yapılmış nesnelerle çevriliyiz, örneğin; bir tabak, bardak, pencere, ayna, mercek, araba camı, damlalık, duş kabini, test tüpü, kolye, avize ve sürahi gibi. Hayatımızın büyük bir parçası haline geldiği halde, camın ne olduğunu veya aldığı şekle nasıl geldiğini düşünmek nerdeyse hiç aklımıza gelmemiştir. Çoğu kimse cam yapımının yaklaşık üç bin yıl önce başladığını ya da iki bin yıl önce camı göze hoş gelen ve kullanışlı formlara

\footnotetext{
* Sorumlu yazar/Corresponding author.

e-posta: syesilay@anadolu.edu.tr
} 
dönüştürmek için geliştirilen tekniklerin bugün cam sanatçıları tarafından hala kullanılmakta olduğunu bilmemektedir. Cam tıpkı taş, taş kesme veya kile benzer olarak modern toplumda her zaman kendine kullanılacak bir yer bulmuştur (Wight, 2011: 1).

Camlar, spektrumun görünür bölgesindeki 1şığ1 ileten az sayıdaki katı maddeler arasındadır. Evlerimizde pencereler ve elektrik lambaları vasıtasıyla 1şık sağlarlar. Camlar hemen hemen optik aletlerin tüm temel öğelerini kendi içlerinde barındırırlar. Dünya çapındaki telekomünikasyon sistemi, optik dalga kılavuzları yoluyla ışı̆̆ın iletilmesine dayanır. Estetik albenisi yüksek olan camların ve kristal avizelerin estetik çekiciliği, kurşun oksidin sağladığı yüksek refraktif indeks ve çift kırılmadan kaynaklanırken, birçok katedralin büyüleyici pencereleri sadece camlarda elde edilebilen parlak renkler nedeniyle hayatımızda yer alabilmektedir.

Camların optik özellikleri üç kategoriye ayrılabilir. İlki camların birçok uygulaması kırılma indisi ve optik dağılım gibi hacimsel (bulk) optik özelliklere dayanmaktadır. İkincisi renk de dâhil olmak üzere diğer özelliklerdir ve bunlar dalga boyunun güçlü fonksiyonları olan optik efektleri temel alır. Sonuncusu ise modern cam teknolojisinde giderek artan bir şekilde kullanılan 1şı̆̆a duyarlılık, 1şıkla renk değiştirme, 1şık saçılımı ve Faraday rotasyonu gibi geleneksel olmayan optik efektler olarak siniflandirilır (Shelby, 2015: 1).

Cam, malzeme ve kullanım olarak kayıtlı tarihten çok öncesine dayanır. Doğal cam üretilmeye başlanmasından çok daha önce ilk kabileler tarafından keşfedilmiş ve şekillendirilmiştir. Obsidiyen olarak adlandırılan bu koyu renkli volkanik cam, volkanik lavların hızlı soğumasıyla doğal olarak oluşan silika esaslı bir malzemedir. Obsidiyen, silisce zengin kayaçların volkanik patlamalar sonucu ergimeye uğradığı birçok bölgede bulunabilir ve bu tür tortular keskin bıçak veya ok başı üretmek üzere kırılabildikleri için tarih öncesi kabileler tarafindan değerli sayılmışlardır (Seth, 2012: 1). Neredeyse tamamen camdan oluşsa da, obsidiyen bazı kristal fazlar (\% 15'den az) ve gaz kabarcıkları içerebilir. Bileşimindeki büyük, küçük veya eser miktardaki elementler obsidiyenin jeolojik geçmişi hakkında bilgi verir (Koen, 2013: 312). Dekoratif kaplamalar cam ürünler üzerine estetik parametrelerinin iyileştirilmesi için uygulanırlar. Dekoratif bir kaplama cam malzeme üzerinde çıkartma, boyama, çizme teknikleri veya silikat esaslı boyalar, bileşikler ve metallerin kaplanması (kısmi veya sürekli) ile elde edilebilir (Bessmertnyi, 2003: 364).

Cam dekorasyon yöntemleri genel olarak üç kategoriye ayrılmaktadır. Birincisi, camın yüzeyini bir şekilde örneğin gravür veya kesme ile işlemeyi, ikincisi resim sanatında olduğu gibi bir yüzey dekorasyonunun uygulanmasını içerir. Üçüncüsü, örneğin mozaik eserinde olduğu gibi, camın diğer cam parçaları ile süslemesine dayanır. Geçmişte en çekici ve başarılı dekorasyonlardan bazıları imalat sırasında uygulanmıştır, ancak çok geniş yelpazedeki teknikler de cam kaplarda üretimlerinden sonra kullanılmıştır (Norman, 2012: 37).

Başlangıçta cam imalatı oldukça yavaş ve masraflıydı. Cam lüks bir üründü ve ulaşılabilirliği azdı. Birinci yüzyılın sonlarında yeni bir teknik olan cam üflemenin icadı cam yapımı tarihinde devrim niteliğinde olmuştur. $\mathrm{Bu}$ buluş Suriyeli esnafa atfedilmiştir. Cam üfleme tekniği cam üretimini daha kolay, daha hızlı ve daha ucuz hale getirmiş ve cam ilk kez sıradan vatandaşlara sunulmuştur. Cam üfleme araç ve teknikleri yüzyıllar boyunca çok az değişmiştir. Cam imalatı, Roma İmparatorluğu'nda gelişip Batı Avrupa'ya ve Akdeniz'e yayılmıştır. Cam, Roma İmparatorluğu sınırlarının ötesinde en önemli ticaret kalemlerinden biri olmuştur. Almanya ve diğer kuzey Avrupa ülkelerinde cam imalatı, 1400'lerin sonları ve 1500'lerin başında önem kazanmıştır. Özellikle 1500'lü yıllarda İngiltere'de üretim artmıştır. İngiliz bir cam yapımc1s1 olan George Ravenscroft (1618-1681) cam tarihinde önemli bir atılım olan kurşunlu camı icat etmiştir. Seri üretim teknolojisi, 1903'te Michael Owens'in gerçekleştirdiği saatte 2500 şişe üretebilen otomatik şişe üfleme makinesinin icadı ile Endüstriyel Devrim'in sonraki evrelerinde başlamıştır. 1950 yılının sonlarında Sir Alastair Pilkington, bugün düz camın \% 90'ının halen üretildiği float cam üretim yöntemini uygulamaya koymuştur. 1890'dan sonra camın gelişimi, üretimi ve kullanımı hızla artmıştır. Cam teknolojinin ilerlemesi ile gelişmektedir ve teknolojik evrim doğal bir süreç olarak devam etmektedir (The Robinson Library, 2017; Carter, 2007).

1980'li ve 1990'lı yıllarda preslenmiş ve üfleme cam eşyaların otomatik olarak üretilmesinde kullanılmak üzere soğuk pigmentlere olan ilgi artmıştır. Kristalden yapılmış cam ürünlerde| sonradan yüzey dekorasyonuna ihtiyaç duyulmuştur, çünkü tüketiciler hem kristal hem de renkli camlara ilgi göstermişlerdir. Bu nedenle, yeni mat renkler geliştirilmiştir (Langhamer, 2003: 272).

Cam renklendirmede kullanılan pigmentlerin üretiminde genellikle maliyeti yüksek saf oksitler bileşimde yer alırlar. Bu durum elde edilen cam ürünün nihai maliyetini de etkiler (Lynn, 2004: 16).

Spinellerin iyi bilinen örnekleri, renkleri siyah olan $\mathrm{FeO} . \mathrm{Fe}_{2} \mathrm{O}_{3}$ ya da $\mathrm{Fe}_{3} \mathrm{O}_{4}$ formülündeki manyetit ve $\mathrm{FeO} . \mathrm{Cr}_{2} \mathrm{O}_{3}$ formülündeki kromittir. Demir bileşikleri, alüminyum silikatlarda ve diğer seramik malzemelerde az veya çok miktarda yer alırlar. Demirin bileşik şeklinde yer aldığı minerallerin sayısı çok fazladır ve birçok mineral az ya da çok demir içerir. Manyetit ve hematit demir oksitleri, limonit hidroksiti, pirit ve markazit ise demirin sülfatlarıdır. Kromit ve manyetit yaygın biçimde kullanılan demirli siyah boyalardır. Basit demir krom sisteminden mükemmel siyah ve gri boyalar üretilmektedir (Ünlütürk, 2005: 16). Elde edilen boyalar oldukça kararlıdır ve metalik leke, iğne deliği, yumurta kabuğu etkisi gibi kusurlar minimumdur. Kromun elde edildiği tek mineral kromittir. Doğada $\mathrm{Fe}_{2} \mathrm{O}_{3} \cdot \mathrm{Cr}_{2} \mathrm{O}_{3}$ halinde bulunan kromit endüstriyel boyutta faydalı olabilmesi için kalsine edilerek boya haline getirilmelidir (Ünlütürk, 2005: 18).

Bu çalışmada sıcak cam üfleme tekniği ile üretilen camlarda, özgün renk ve dokuya sahip, sanatsal etkileri kuvvetlendirebilecek yüzeyler oluşturmak amaciyla ticari pigment kullanımı yerine maliyeti daha düşük olan manyetit ve kromit hammaddeleri kullanılmıştır.

Cam eşyaların yüzeylerinin renk ve doku etkisi elde etmek amacı ile dekorlanması antik çağa kadar uzanır ve Mısır ve Roma zamanlarında yaygın şekilde kullanılmıştır. Günümüzde teknolojinin ilerlemesi ile malzemelerin özelliklerinin daha iyi kavranması sonucunda özellikle plastik sanatlar alanında kullanılan malzeme çeşitliliği de 
artmıştır. Cam doğası gereği birçok malzeme ile uyum sağlayabildiği için gerçekleştirilen bu çalışmada yenilikçi bir uygulama olarak cam yüzeyinde seramik hammaddelerin kullanım etkileri araştırılmıştır.

$\mathrm{Bu}$ amaçla sıcak cam üfleme tekniği ile elde edilen camların yüzeylerine sarma yöntemi ile belli bir tane boyutuna sahip olan manyetit ve kromit tozları uygulanmıştır. Uygulamalar hem şeffaf hem de renkli cam yüzeylerinde gerçekleştirilmiştir. Tozlar yüzeye alındıktan sonra gerçekleştirilen tasarıma göre üstüne bir katman daha cam alınmadan en son katman olarak ve üzerine cam alınarak cam katmanları arasında kalacak şekilde üretimler yapılmıştır.

\section{Stüdyo Çalışmaları ve Testler}

İlk olarak çalışmada kullanılacak kromit ve manyetitin kimyasal analizleri yapılarak bileşimleri belirlenmiştir. Daha sonra kromit ve manyetit \% 50 su ilavesiyle alümina bilyeli değirmenlerde 8 saat süre ile öğütülmüş ve 100 mesh'lik elekten süzülmüştür. $105{ }^{\circ} \mathrm{C}$ 'de etüvde 1 gün süre ile kurutulmuştur. Kurutma işleminin ardından tozların tane boyutu ölçümleri yapılmıştır. Manyetit ve kromit karışımları ham halde, kalsine edilmeden cam yüzeylerinde kullanılmıştır.

Şekil 1. Sıcak Cam Üfleme Üretim Aşamaları
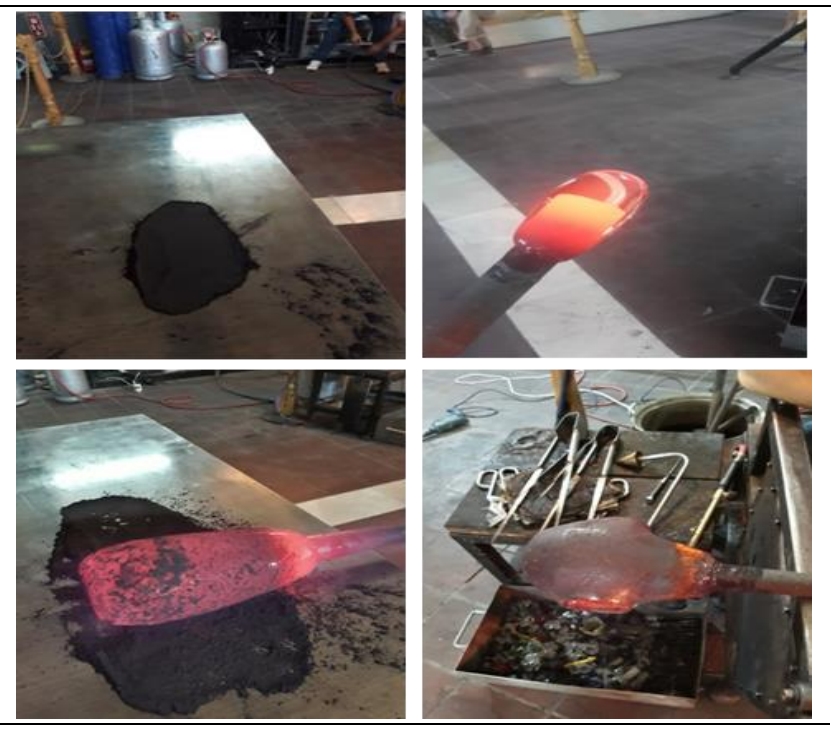

Sicak cam uygulamalarında manyetit ve kromit tozları metal zemin üzerine dökülmüştür. Ardından ergitme fırınından alınan ve fiska olarak adlandırılan cam metal piponun ucuna sarılmıştır (Şekil 1). Üfleme yoluyla istenilen büyüklükte cam elde edilmesinden sonra cam yüzeyine manyetit ve kromit tozları sarılmış ve ardından trommelde bekletilerek tozların cam bünye ile bütünleşmesi sağlanmıştır. Bu işlem arka arkaya 3 defa tekrarlanmıştır. Uygulama sürecinde malzemenin yüzeye tam kaynaşmadığ görülünce pürmüz (Şaloma) yardımı ile yüksek ısı transferi sağlanıp ardından cam tekrar trommelde isitılmıştır. Uzun bir isıtma sürecinden sonra yüzey koyu metalik gri renk almış ve kullanılan tozlar cam yüzeyine tamamen yayılmıştır. Elde edilen çekirdek olarak tabir ettiğimiz camın biraz soğumasından sonra ergitme firınından bir katman daha cam sarılarak cam kütlesi büyütülmüştür. Planlanan tasarıma göre üfleme ve şekillendirme uygulamaları yapılmıştır. Şekillendirme işleminin ardından cam 1 gün süreyle tavlama fırınında tutulduktan sonra kesme rodajlama işlemleri ile nihai formuna getirilmiştir.

Sıcak cam uygulamalarının ikinci aşamasında ise manyetit ve kromit uygulamaları renkli cam zemine uygulanarak işlemler aynı sırada gerçekleştirilmiştir.

\section{Bulgular}

Manyetit ve kromit tozlarına ait kimyasal bileşim analizi sonucu Tablo 1'de sunulmuştur.

Tablo 1. Manyetit ve Kromit Cevherlerinin Oksit Bileşimleri

\begin{tabular}{ccc}
\hline Hammadde & Kromit & Manyetit \\
\hline $\mathrm{Cr}_{2} \mathrm{O}_{3}$ & 42,12 & 0,62 \\
$\mathrm{Fe}_{2} \mathrm{O}_{3}$ & 24,34 & 90,19 \\
$\mathrm{MgO}$ & 16,39 & 3,40 \\
$\mathrm{SiO}_{2}$ & 6,49 & 3,12 \\
$\mathrm{Al}_{2} \mathrm{O}_{3}$ & 10,11 & 1,10 \\
$\mathrm{CaO}$ & 0,22 & 1,47 \\
$\mathrm{ZnO}$ & 0,17 & - \\
$\mathrm{TiO}$ & 0,16 & - \\
$\mathrm{MnO}$ & - & 0,06 \\
$\mathrm{~K}_{2} \mathrm{O}$ & - & 0,03 \\
\hline
\end{tabular}

Tozların oksit bileşimini belirlemek için yapılan XRF (X Işınları Floresansı) analizi sonuçlarına göre kromit ve manyetitin yüksek oranda $\mathrm{Fe}_{2} \mathrm{O}_{3}$ (demir oksit) içerdikleri görülmektedir.

Tozlara ait tane boyutu ölçüm sonuçları Şekil 2'de görülmektedir.

Şekil 2. Tozlara Ait Tane Boyutu Dağılım Eğrileri

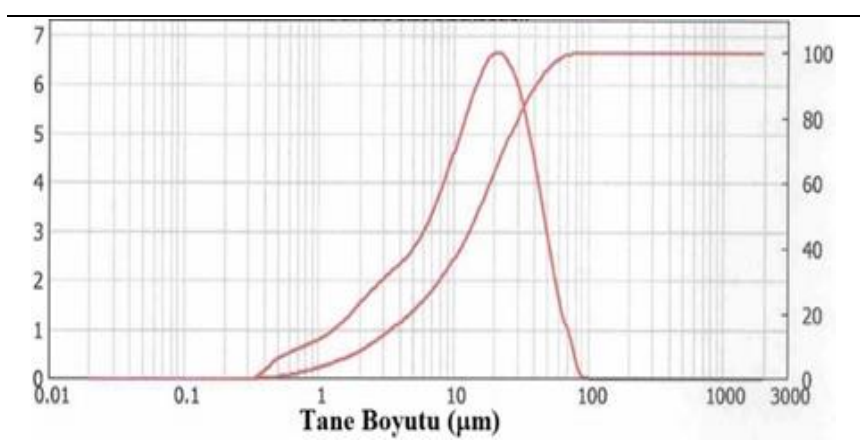

a) Kromit

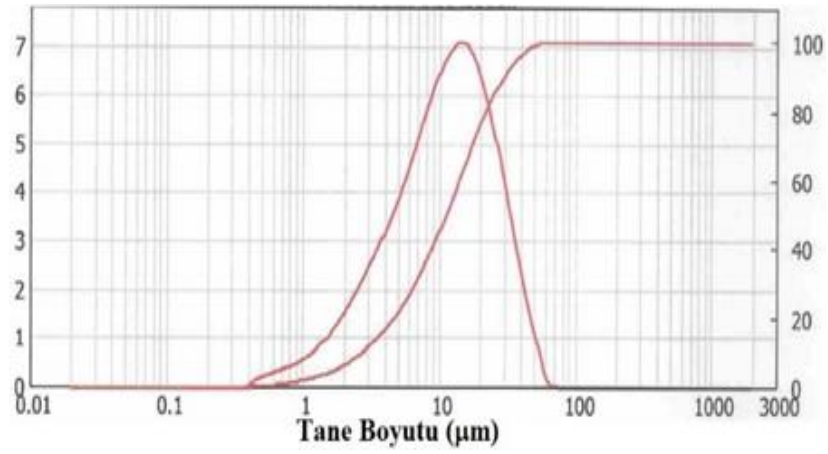

b) Manyetit

Sonuçlara göre kromit cevherinin ortalama tane boyutu $14.84 \mu \mathrm{m}$, manyetitin ise $11.276 \mu \mathrm{m}$ olarak saptanmıştır.

Sicak cam üfleme tekniğinde kromit ve manyetitin cam yüzeylerinde uygulanması sonucunda elde edilen sanatsal camların görüntüleri Şekil 3-7'de verilmiştir. 
Şekil 3. Şeffaf Cam Üzerine Uygulanan Manyetit ve Beyaz Toz İle Renklendirilmiş Cam Gövde Üzerine Uygulanan Kromit İle Yapılan Tasarımlar

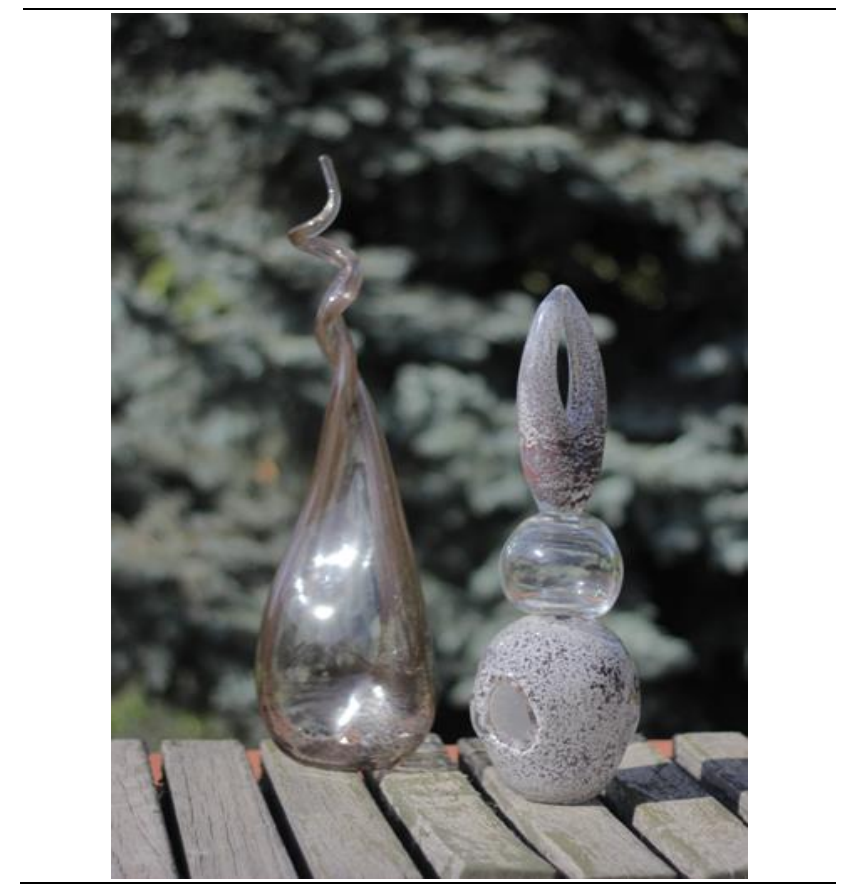

Şekil 3'te şeffaf cam üzerine uygulanan manyetit ve beyaz toz ile renklendirilmiş cam gövde üzerine uygulanan kromit ile yapılan tasarımlarda farklı doku etkileri elde edilmiştir.

Şekil 4. Şeffaf Cam Bünyeler Üzerinde Kromitin Kullanılmasıyla Üretilen Tasarımlar

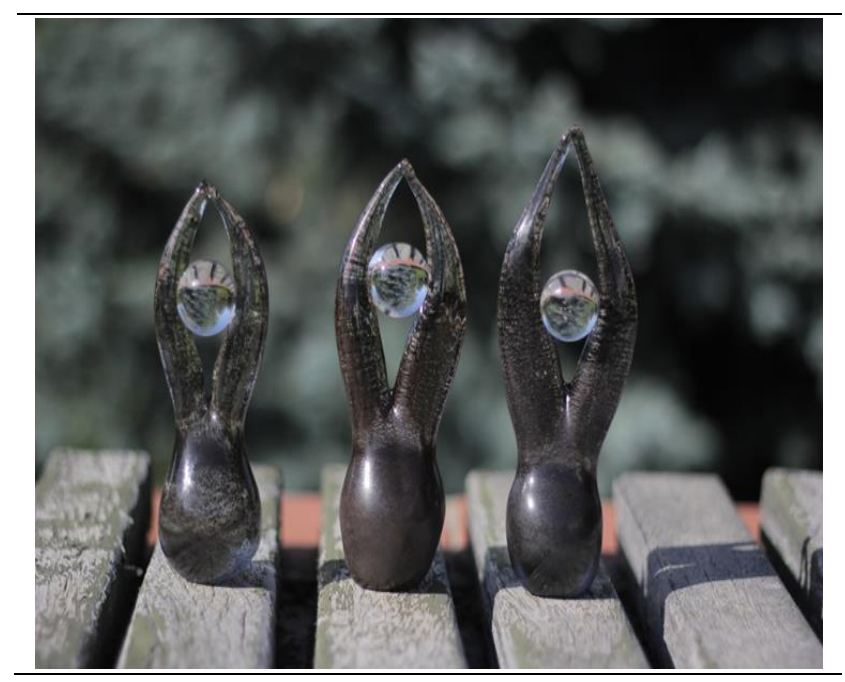

Şekil 4'te görülen şeffaf cam bünyeler üzerinde kromitin kullanılmasıyla üretilen tasarımlarda kromitin yoğun bir şekilde yüzeye uygulanması sonucunda metalik bir etki elde edilmiştir.

Şekil 5'de görülen uygulamada şeffaf cam üzerine sarı renk uygulanmıştır ve ardından yüzeyde manyetit tozları kullanılmıştır. Nihai aşamada yüzeye bir katman cam daha alınarak manyetit tozlarının cam katmanları arasında kalması sağlanmış ve form elde edilmiştir. Yüzeyde elde edilen renk geçiş etkili ve metalik dokuya sahiptir.
Şekil 5. Şeffaf Cam Üzerinde Öncelikle Sarı Renk ve Ardından Yüzeyde Manyetit Tozları Kullanılarak Üretilen Cam

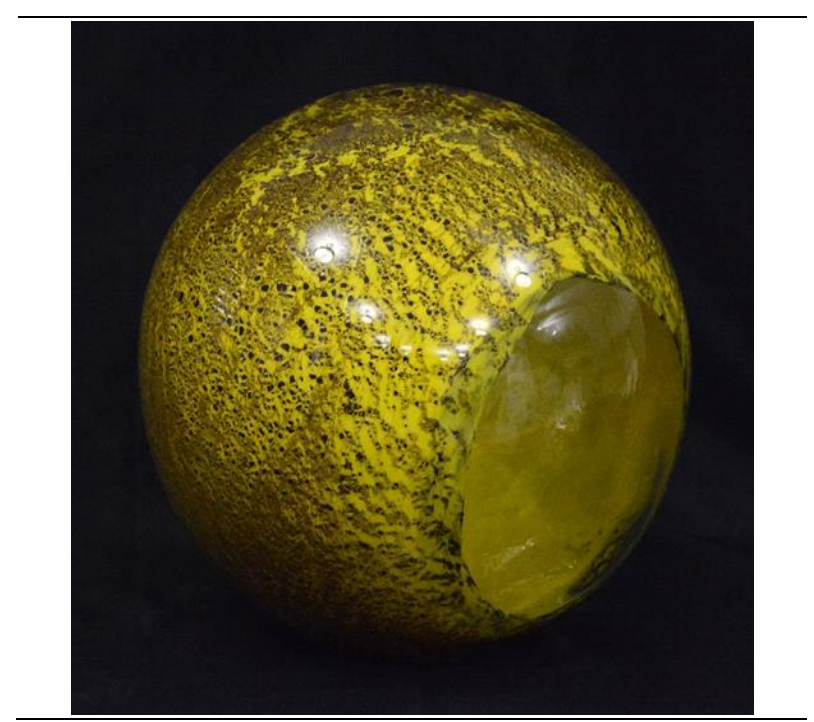

Şekil 6`da görülen tasarımda mavi tabanlı renk üzerine alınmış manyetit tozları oldukça homojen bir şekilde cam yüzeyinde dağılmıştır. Manyetit kullanımı yüzeydeki mavi rengin tonunu daha da zenginleştirerek kratere benzeyen bir etki yaratmıştır.

Şekil 6. Mavi Tabanlı Renk Üzerine Alınmış Manyetit Kullanılarak Üretilen Cam

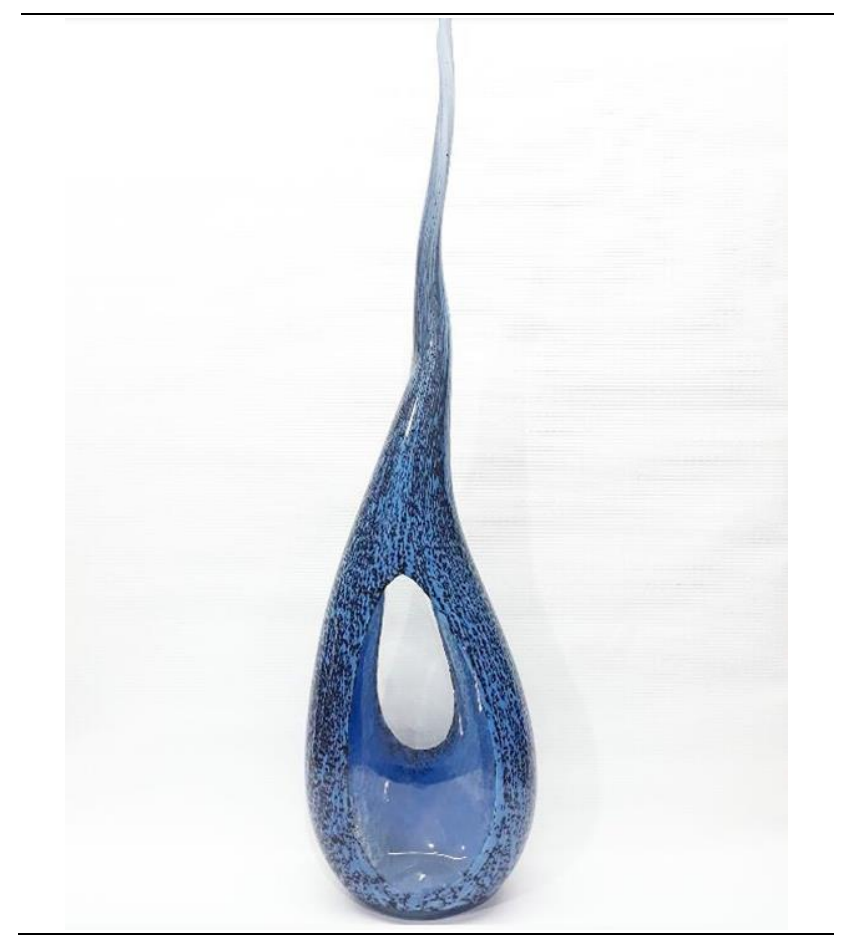

Şekil 7'de görülen uygulamada opak sarı renk üzerine manyetit tozları alındıktan sonra en dışa bir katman daha cam sarılmıştır. Yüzeyde homojen dağılıma sahip krater benzeri bir etki yaratmıștır. Formun üst kısmında manyetit tozları şeffaf mavi renk üzerine alınmış ve tekrar bir katman cam alınmamıştır. Sarı renkli camdakine göre daha az etki meydana gelmiştir. 
Şekil 7. Opak Sarı ve Mavi Renkli Cam Yüzeyinde Manyetit Kullanımıyla Elde Edilen Tasarım

\section{Sonuç ve Değerlendirme}

Dekorasyon sürecinde cam doğası gereği 1şıkla olan etkileşimi, sanatsal ve estetik değeri ve mekanik dayanımı açısından avantaj sağlayan, fonksiyonel ve oldukça yaygın kullanılan bir malzemedir. Farklı dekorasyon stilleri için de daha geniş sanatsal tasarım olanakları sağlar. Aynı zamanda cam başka birçok malzeme ile birlikte kullanılabilme özelliğinden dolayı da farklı disiplinleri bir araya getirme potansiyeline sahiptir. Antik çağlardan günümüze kadar araştırmacılar, cam sanatında farklı ve özgün çalışmalar yapmakta ve yeni malzemelerle camın etkileşimlerini araştırmaktadırlar.

$\mathrm{Bu}$ çalışmada endüstriyel pigmentler yerine cam yüzeyinde renk ve farklı sanatsal etkiler elde etmek amaciyla manyetit ve kromit cevherleri sicak camlarda uygulanarak etkileri incelenmiștir. Üretilen sıcak cam formlarında bu cevherlerin cam yüzeylerine ayrı ayrı kullanıldığında açık kahverenginden siyah renk tonlarına kadar değişen bir renk aralığ verdiği gözlenmiştir.

Üretim sürecindeki en önemli parametrelerden biri, yüzeyde kullanılacak malzemenin cam bünyesiyle uyumlu olması ve cam yüzeyinde topaklanma olmadan homojen olarak dağılım gösterebilmesidir. Bu çalışmada kromit ve manyetitin camın şekillendirme olanaklarını kısıtlamamış olması elde edilen formların çeşitliliği ve zenginliği açısından avantaj sağlamıştır. Ayrıca malzemelerin cam formla olan uyumu üretimin seri olmasını sağlamış ve birçok kez deneme yapma olanağı sunmuştur. Burada önemli parametrelerden biri de renk verici tozların tane boyutlarının çok düşük olmasıdır. Düşük tane boyutundan dolayı manyetit ve kromitin cam yüzeyiyle bütünleşme özelliklerinin arttığı düşünülmektedir. Tozların cam yüzeyiyle bütünleşebilmesi için yüksek sıcaklıkta ekstra işlem görmesi çalışmanın gelişmeye açık yönü olarak değerlendirilebilir. Cam yüzeyi ile bütünleşmeyi arttırarak enerji maliyetini düşük tutmak için gelecek çalışmalarda tozların tane boyutu daha da düşürülebilir ya da tozlar düşük ergime sıcaklığına sahip şeffaf bir firit ile karıştırılabilir. Böylece firitin düşük sıcaklıkta yumuşaması ile tozlar ilave 1 sıl işleme gerek kalmadan yüzeye daha kolay tutunabilecektir.

Her sanatçı bir ifade biçimi olarak kendi tekniğini, formunu, kullanır. Burada kullanılan manyetit ve kromitin cam yüzeyine verdiği dereceli renk tonları ve homojen dağılım etkisi sınırlı sayıda malzeme ile sağlanabildiği için süreci daha özgün kılmaktadır.

Ülkemizde cam sanatının kabul gören sanat dallarından birisi haline gelmesi ve üniversite düzeyinde cam eğitimine verilen önemin gün geçtikçe artması ile bu alandaki literatür araştırmalarının da ivme kazandığı düşünülmektedir. Çalışmada elde edilen bulguların cam alanında öğrencilere, akademisyenlere ve sanatçılara katkı sağlayacağı ön görülmektedir.

\section{Kaynakça}

Abidin, S. Z., Legino, R., Noor, H. M., Vermol, V. V., Anwar, R., \& Kamaruzaman, M. F. (Eds.). (2016). Proceedings of the 2nd International Colloquium of Art and Design Education Research (i-CADER 2015). Singapore: Springer.

Bessmertnyi, V. S., Min'ko, N. I., Krokhin, V. P., Semenenko, S. V., \& Osykov, A. I. (2003). Trends in Contemporary Methods for Decoration of Glass and Glass Articles (A Review). Glass and Ceramics, 60(11), 364-366.

Carter, C. B., \& Norton, M. G. (2007). Ceramic materials: science and engineering. USA: Springer Science \& Business Media.

Janssens, K. H. (Ed.). (2013). Modern Methods for Analysing Archaeological and Historical Glass. UK: John Wiley \& Sons.

Langhamer, A. (2003). The Legend of Bohemian Glass: A Thousand Years of Glassmaking in the Heart of Europe. Tigris: Spol.S.R.O.

Lynn, M. D. (2004). American Studio Glass, 1960-1990. USA: Hudson Hills.

Norman, B. (2012). Engraving and Decorating Glass: Methods and Techniques. Canada: Courier Corporation.

Rasmussen, S. C. (2012). How Glass Changed the World: The History and Chemistry of Glass from Antiquity to the 13th Century. USA: Springer Science \& Business Media.

Shelby, J. E. (2005). Introduction to Glass Science and Technology. UK: Royal Society of Chemistry.

The Robinson Library (2017). A Brief History of Glass and Glassmaking. (Erişim: 24.09.2017), http://www.robinsonlibrary.com/technology/chemical/cl ay/glasshistory.htm

Ünlütürk, G. (2005). Elektroporselenlerde Kullantlan Kahverengi Pigmentin Endüstriyel Atıklardan ve Doğal Hammaddelerden Üretimi. Yüksek Lisans Tezi. İstanbul: İstanbul Teknik Üniversitesi.

Wight, K. (2011). Molten Color: Glassmaking in Antiquity. Los Angeles: J. Paul Getty Museum. 